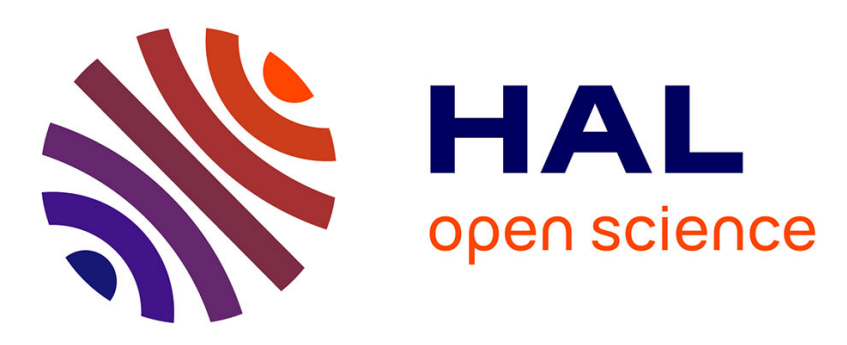

\title{
Investigation of magnetic composites using as photocatalyst and antibacterial application
}

Hassan Beigi Rizi, Khalil Gheisari, Hossein Motamedi, Michaël Pereira, Mohammadali Shirinbayan

\section{- To cite this version:}

Hassan Beigi Rizi, Khalil Gheisari, Hossein Motamedi, Michaël Pereira, Mohammadali Shirinbayan. Investigation of magnetic composites using as photocatalyst and antibacterial application. Inorganic Chemistry Communications, 2020, 119, pp.1-12. 10.1016/j.inoche.2020.108031 . hal-02890417

\section{HAL Id: hal-02890417 https://hal.science/hal-02890417}

Submitted on 6 Jul 2020

HAL is a multi-disciplinary open access archive for the deposit and dissemination of scientific research documents, whether they are published or not. The documents may come from teaching and research institutions in France or abroad, or from public or private research centers.
L'archive ouverte pluridisciplinaire HAL, est destinée au dépôt et à la diffusion de documents scientifiques de niveau recherche, publiés ou non, émanant des établissements d'enseignement et de recherche français ou étrangers, des laboratoires publics ou privés. 


\title{
Investigation of magnetic composites using as photocatalyst and antibacterial application
}

\author{
Faezeh Hashemi ${ }^{\mathrm{a}}$, Hassan Beigi Rizi ${ }^{\mathrm{b}, \mathrm{c}}$, Khalil Gheisari ${ }^{\mathrm{c}}$, Hossein Motamedi ${ }^{\mathrm{d}}$, Michaël Pereira ${ }^{\mathrm{b}}$, \\ Mohammadali Shirinbayan ${ }^{\mathrm{b}, \mathrm{e}, *}$ \\ ${ }^{a}$ Department of Chemical Engineering, School of Chemical and Petroleum Engineering, Shiraz University, Shiraz, Iran \\ ${ }^{\mathrm{b}}$ Arts et Metiers Institute of Technology, CNAM, LIFSE, HESAM University, F-75013 Paris, France \\ ${ }^{\mathrm{c}}$ Department of Materials Science and Engineering, Faculty of Engineering, Shahid Chamran University of Ahvaz, Ahvaz, Iran \\ ${ }^{\mathrm{d}}$ Biotechnology and Biological Science Research Center, Shahid Chamran University of Ahvaz, Ahvaz, Iran \\ ${ }^{\mathrm{e}}$ Arts et Metiers Institute of Technology, CNAM, PIMM, HESAM University, F-75013 Paris, France
}

\section{G R A P H I C A L A B S T R A C T}

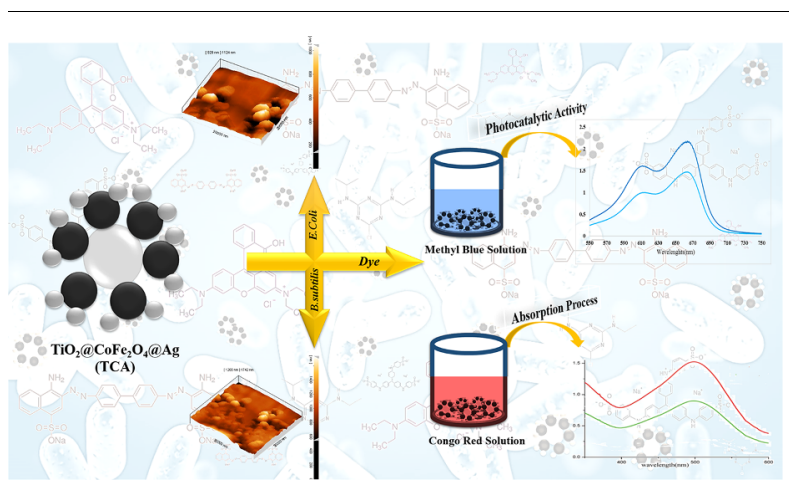

\section{A R T I C L E I N F O}

\section{Keywords:}

Magnetic composite

Photocatalyst

Sorption kinetics

Antibacterial measurement

\begin{abstract}
A B S T R A C T
This study shows the inactivation of antibacterial and dye removal in aqueous solution via photocatalysis with an easy fabrication route of silver deposited titanium dioxide/cobalt ferrite composite nanoparticles through a three-stage process applied under ultrasonic irradiation. An adsorption kinetic and equilibrium isotherm were investigated by four kinetic and five isotherm models. Then, photocatalytic potential and antibacterial activity were assessed, respectively, by photodegradation of cationic dye under UV light and four bacteria employing MIC and MBC indices coupled to SPM observation, which illustrated that the bactericidal effect is desirable to inhibit growth. Moreover, the nanocomposite can be easily isolated from the solution via magnetic decantation for removing catalytic pollutants.
\end{abstract}

\section{Introduction}

It is crystal clear that the rapid development of the humane society has been responsible for environmental problems and troubles, among which is the contamination of drinking water by different residues like dyes, agrichemicals and microbial pathogens. It is recognized and proved that dye cannot be removed from water by commonly known wastewater treatment procedures, once released from their

E-mail addresses: F-hashemi@phdstu.scu.ac.ir (F. Hashemi), Hassan.beigi_rizi@ensam.eu (H.B. Rizi), khgheisari@scu.ac.ir (K. Gheisari), motamedih@scu.ac.ir (H. Motamedi), michael.pereira@ensam.eu (M. Pereira), Mohammadali.Shirinbayan@ensam.eu (M. Shirinbayan). 


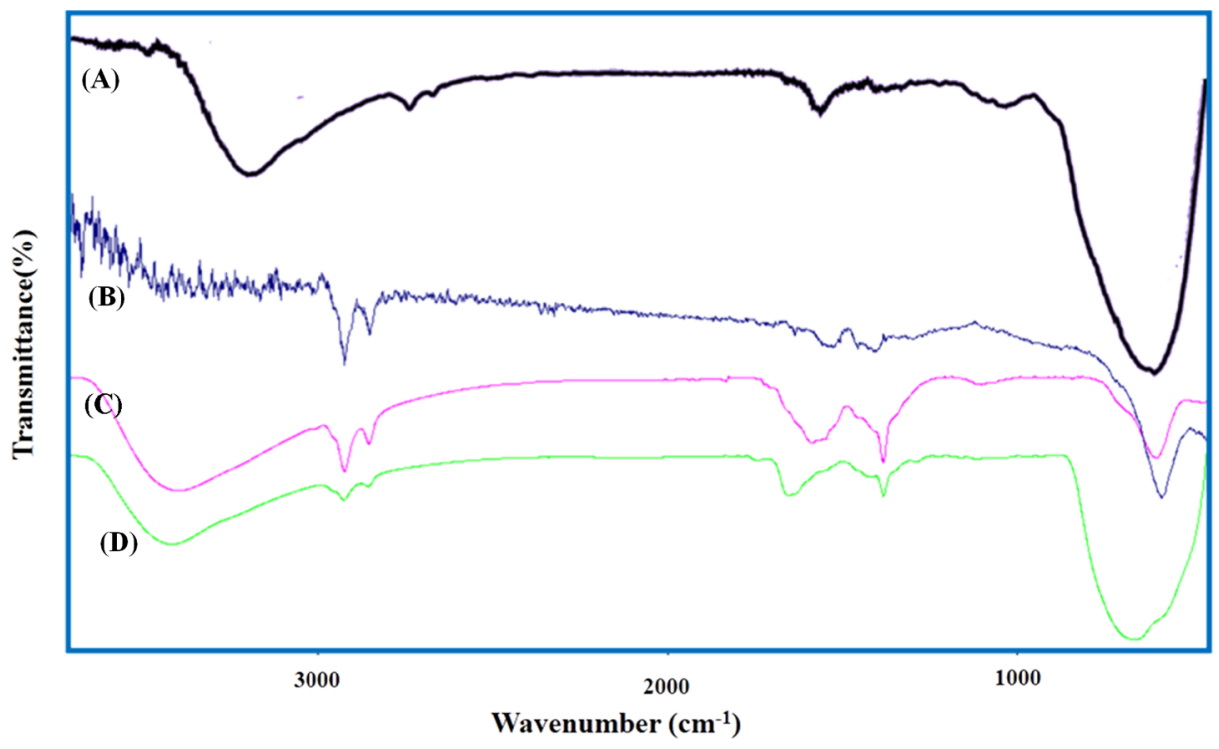

Fig. 1. FT-IR spectra of $\mathrm{TiO}_{2}$ (A), $\mathrm{CoFe}_{2} \mathrm{O}_{4}$ (B), TC (C) and TCA (D).

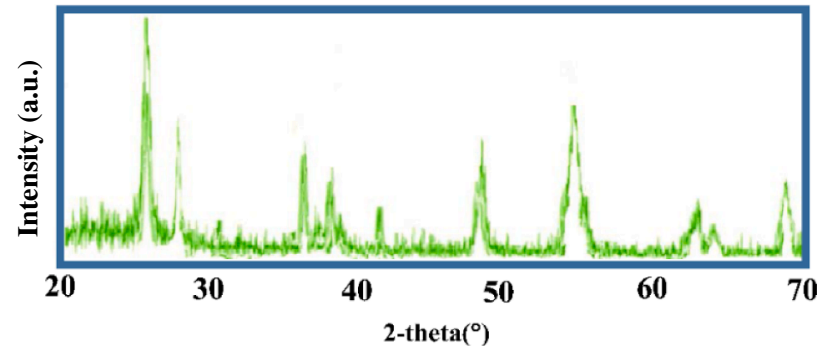

Fig. 2. XRDP pattern of as-prepared TCA sample.

manufacturing methods [1-4]. Various techniques have been occupied for the removal of dyes, including chemical oxidation, coagulation, electrochemical oxidation, photodegradation, and adsorption, in which adsorption and photodegradation are considered superior to the other techniques due to their relatively easy operation, cost-effective and convenience products [5].

However, semiconductor heterogeneous photocatalysts, as one of the most advanced physicochemical catalysts, have been extensively investigated for photodegradation of dye. Among the semiconductor compounds, titanium dioxide $\left(\mathrm{TiO}_{2}\right)$ is the greatest widely applied heterogeneous catalyst because of strong oxidizing agent, non-toxicity and chemical/thermal stability. It is showed that by UV irradiation of $\mathrm{TiO}_{2}$, electrons in the valence band (VB) will jump to the conduction band (CB) and an electron-hole pair is produced, subsequently [6-13]. The pairs of electron-hole will play a role as a strong oxidizing agent that can attack organic molecules like; Rhodamine B (RB), methylene blue (MB) dye and atrazine pesticide, or those located near to the surface of the catalyst, thus, it could achieve rapidly and completely degradation to the inorganic products [14-19]. The tetragonal Anatase of $\mathrm{TiO}_{2}$, with a bandgap of $3.2 \mathrm{eV}$ can be photoexcited when it is subjected to the irradiation of UV-light, which is just roughly $2-5 \%$ of total sunlight [10,20-25]. Therefore, growing attention have been paid in the literature to improve its photocatalysis capabilities, such as the synthesis of $\mathrm{TiO}_{2}$ immobilized on either $\mathrm{Fe}_{3} \mathrm{O}_{4}$ or other magnetic nanoparticles [26]. However, more fascinating $\mathrm{TiO}_{2}$-magnetic nanocomposites can be produced by coating of a $\mathrm{TiO}_{2}$ core with a layer of magnetic, and subsequently by immobilizing of extra nanoparticles on the surface of the magnetic shell.

Disinfection procedure represents a crucial step in centralized wastewater treatment to control infectious pathogens. As a consequence, finding an effective disinfectant that produces less dangerous

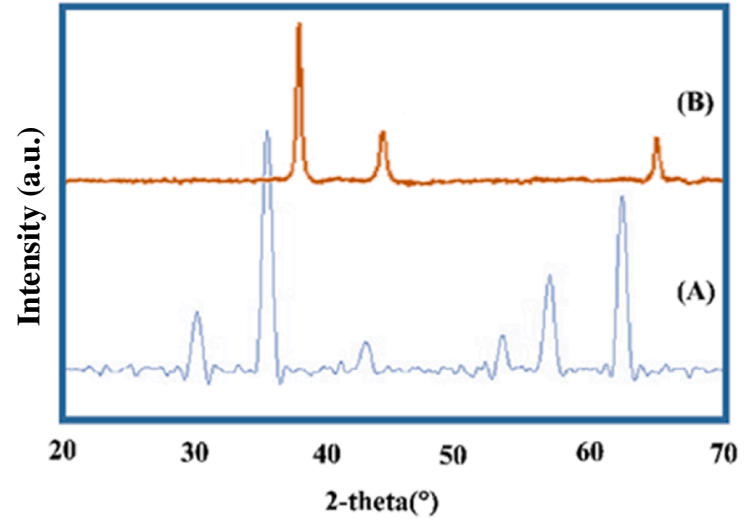

Fig. 3. XRD patterns of as-prepared $\mathrm{CoFe}_{2} \mathrm{O}_{4}$ (A), AgNPs (B) samples.

disinfection by-products and sustained antimicrobial activity is of importance. Besides, silver nanoparticles (AgNPs) have recently expressed keen interest due to their distinct properties and potential applications in the biomedical field of research $[27,28]$. They have been broadly studied because of their well-documented antimicrobial agents [29]. Furthermore, AgNPs have a wide-range antibacterial activity to kill and remove a multiplicity of bacteria existing in everyday life including those that are antibiotic-resistant [30]. The problem encountered in using Ag-based antimicrobial properties is the recovery of these disinfectants. Recently, the studies have confirmed that AgNPs are toxic to aqua system and therefore must be efficiently removed from the disinfected media [31-33]. The combination of AgNPs with $\mathrm{TiO}_{2}$ magnetic system can provide a suitable means for efficient removal of silver nanoparticles and $\mathrm{TiO}_{2}$ from solution, simultaneously. To the best of our knowledge, there are a few literature conducted research into the synthesis of nanocomposite with the related potential applications, like adsorption-desorption, photocatalytic and antibacterial activity. This study investigates $\mathrm{TiO}_{2} @ \mathrm{CoFe}_{2} \mathrm{O}_{4} @ \mathrm{Ag}$ (TCA), the magnetic nanocomposite through a straightforward three-step procedure. Instead of Magnetite $\left(\mathrm{Fe}_{3} \mathrm{O}_{4}\right)$, we chose $\mathrm{CoFe}_{2} \mathrm{O}_{4}$ due to its stability in the air atmosphere during preparation and heat treatments. In more detail, $\mathrm{Fe}_{3} \mathrm{O}_{4}$ can readily change to $\mathrm{Fe}_{2} \mathrm{O}_{3}$ by the oxidation process if not subjected to an inert atmosphere, which causes loss of magnetic properties. Additionally, the anchoring of silver and $\mathrm{TiO}_{2}$ nanoparticles with the $\mathrm{CoFe}_{2} \mathrm{O}_{4}$ can prevent their aggregation in solution. 

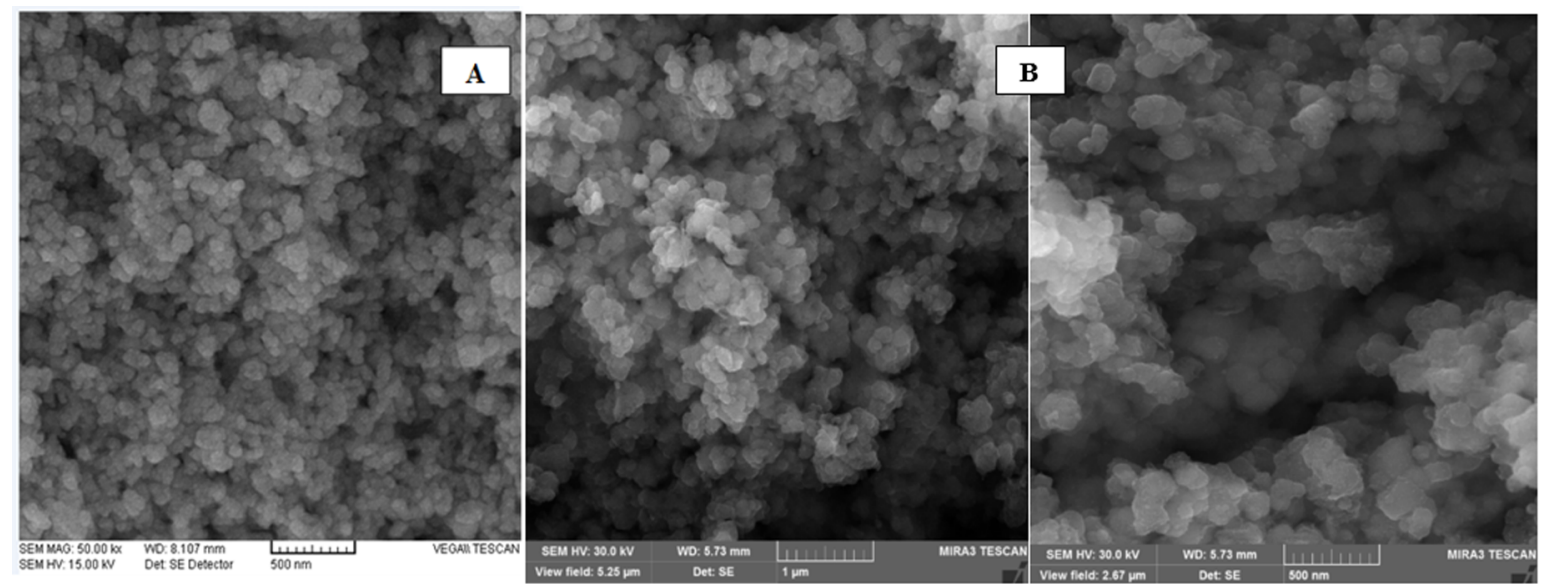

Fig. 4. SEM images of as-synthesized $\mathrm{CoFe}_{2} \mathrm{O}_{4}$ (A) and TCA (B) samples.
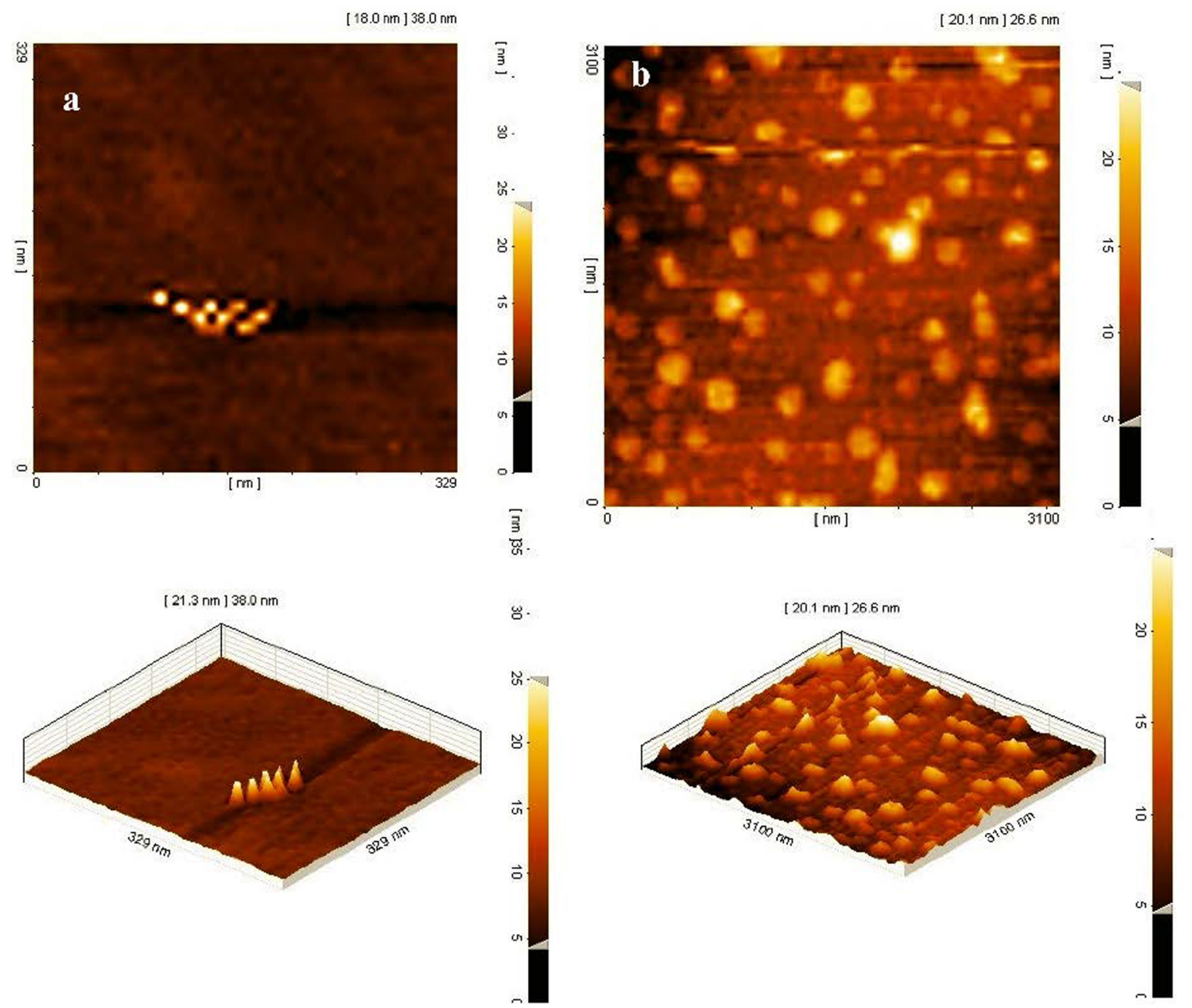

Fig. 5. AFM images of as-synthesized $\mathrm{TiO}_{2}$ (A) and TC (B) samples.

\section{Experimental procedures}

\subsection{Materials and methods}

The starting materials were of a generic quality that used without further purification obtained from Merck and Fluke. FT-IR spectra were obtained by an FT BOMEM MB102 spectrophotometer. X-ray diffraction powder (XRDP) pattern of TCA nanocomposite was taken with a Philips
X-ray diffract meter (Model PW1840) over a $2 \theta$ range from 20 to $70^{\circ}$ using $\mathrm{Cu} \mathrm{K} \alpha$ radiation $(\lambda=1.540 \mathrm{~A})$. Plus, transmission electron microscopy (TEM) applying a Philips CM10-HT 100KV microscopy with the aim of calculating the size distribution and morphology of nanocomposite. The scanning electron microscopy (SEM) images of nanocomposite and $\mathrm{CoFe}_{2} \mathrm{O}_{4}$ were prepared by a Hitachi Japan S4160. Magnetic properties of the as-prepared TCA nanocomposite and $\mathrm{CoFe}_{2} \mathrm{O}_{4}$ were considered using Vibrating Sample Magnetometer (VSM) 


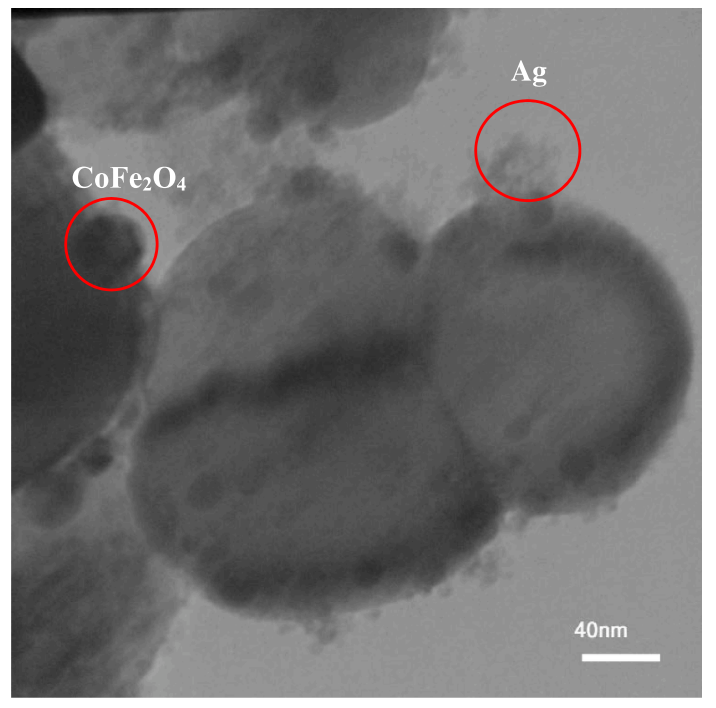

Fig. 6. TEM image of the three-component TCA nanocomposite.

of Meghnatis Daghigh Kavir Company. All images of scanning probe microscopy (SPM) were obtained via a Denmark DS 95-50E.

\subsection{Synthesis}

\subsubsection{Synthesis of TCA nanocomposite}

$\mathrm{TiO}_{2}$ nanoparticles were firstly produced via hydrothermal method with respect to the procedure reported by Malekshahi et al. [34]. After, the pre-synthesized $\mathrm{TiO}_{2}$ nanoparticles were coated with a layer of $\mathrm{CoFe}_{2} \mathrm{O}_{4}$ through co-precipitation method to prepare the two-component TC composite. In the last step, AgNPs were formed and inlaid onto the surface of the TC composite via chemical reduction of silver nitrate $\left(\mathrm{AgNO}_{3}\right)$ [35]. In this procedure, $0.2 \mathrm{~g}$ of TC composite was dispersed in $15 \mathrm{~mL}$ of deionized water containing $1 \mathrm{~g}$ of polyvinyl pyrrolidone (PVP), $0.96 \mathrm{~g}$ of $\mathrm{NaOH}, 1 \mathrm{~g}$ of glucose at ambient temperature under ultrasonic irradiation. In addition to that, $0.1 \mathrm{M}(5 \mathrm{~mL})$ of the $\mathrm{AgNO}_{3}$ solution was added drop by drop. Then, the mixture was further sonicated for $3 \mathrm{~h}$. The prepared TCA nanocomposite was subsequently separated from the solution by magnetic decantation and washed with distilled water several times to get rid of any excess of protecting agent and sodium hydroxide. In the end, the product was dried at $80{ }^{\circ} \mathrm{C}$ for $10 \mathrm{~h}$.

\subsection{Adsorption measurement}

Adsorption experiments were carried out with the synthesized TCA nanocomposite by utilizing a batch technique, which was conducted individually for CR dye by performing a similar procedure as detailed below. An aliquot of $25 \mathrm{~mL}$ of the dye solution, with selected initial concentration (30-60 mg. $\mathrm{L}^{-1}$ ) was transferred into a beaker. A determined dosage of the nanocomposite $3 \mathrm{mg}$ was added to the beaker. After mixing time ( $3 \mathrm{~min}$ ) elapsed, the TCA nanocomposite was separated magnetically. The final dye residue concentration in the supernatant was determined by UV-Visible spectrometer. The percent adsorption of each dye, the dye-removal efficiency of TCA, was calculated through the following equation:

$\%$ Adsorbtion $=\frac{(\mathrm{C} 0-\mathrm{Cf})}{\mathrm{C} 0} \times 100$

where $\mathrm{C}_{0}$ and $\mathrm{C}_{\mathrm{f}}$ represent the initial and after adsorption dye concentration in the aqueous phase, respectively.

\subsection{Photocatalytic degradation}

The $50 \mathrm{~mL}$ of dye solution was sampled as a model pollutant to investigate the photocatalytic activity. $100 \mathrm{mg}$ catalyst was, then, applied for degradation of $50 \mathrm{~mL}$ solution. Next, the dye solution was mixed by a stirrer for $2 \mathrm{~h}$ in a dark environment to optimize the adsorption of dye by the catalyst and, consequently, better availability of the surface. The solution was irradiated by a $350 \mathrm{~W}$ UV-lamp which was placed in a quartz pipe in the middle of the reactor. It was turned on after $1 \mathrm{~h}$ stirring the solution and sampling (about $1 \mathrm{~mL}$ ) was done every $30 \mathrm{~min}$. After filtration and centrifuging, the samples were evaluated based on concentration by UV-visible spectrometry.

\subsection{Antibacterial measurements}

According to the macro broth dilution method, the minimum inhibitory concentration (MIC) of TCA nanocomposite was investigated. A serial of two-fold dilutions from 16 to $1 \mathrm{mg} \cdot \mathrm{mL}^{-1}$ of the mentioned nanocomposite was prepared in $1 \mathrm{~mL}$ of Mueller-Hinton broth (MHB, Merck, Germany). In the next step, $100 \mu \mathrm{L}$ of Escherichia coli (ATCC 25299), Pseudomonas aeruginosa (ATCC9027), Bacillus subtilis (ATCC6633) and Staphylococcus aureus (ATCC6538) suspensions with 0.5 McFarland turbidity were separately inoculated in prepared cultures and following incubation at $37{ }^{\circ} \mathrm{C}$ for $24 \mathrm{~h}$ the bacterial growth was examined. MIC was regarded as the least concentration at which bacterial growth was inhibited. Subsequently, a loop full of growth

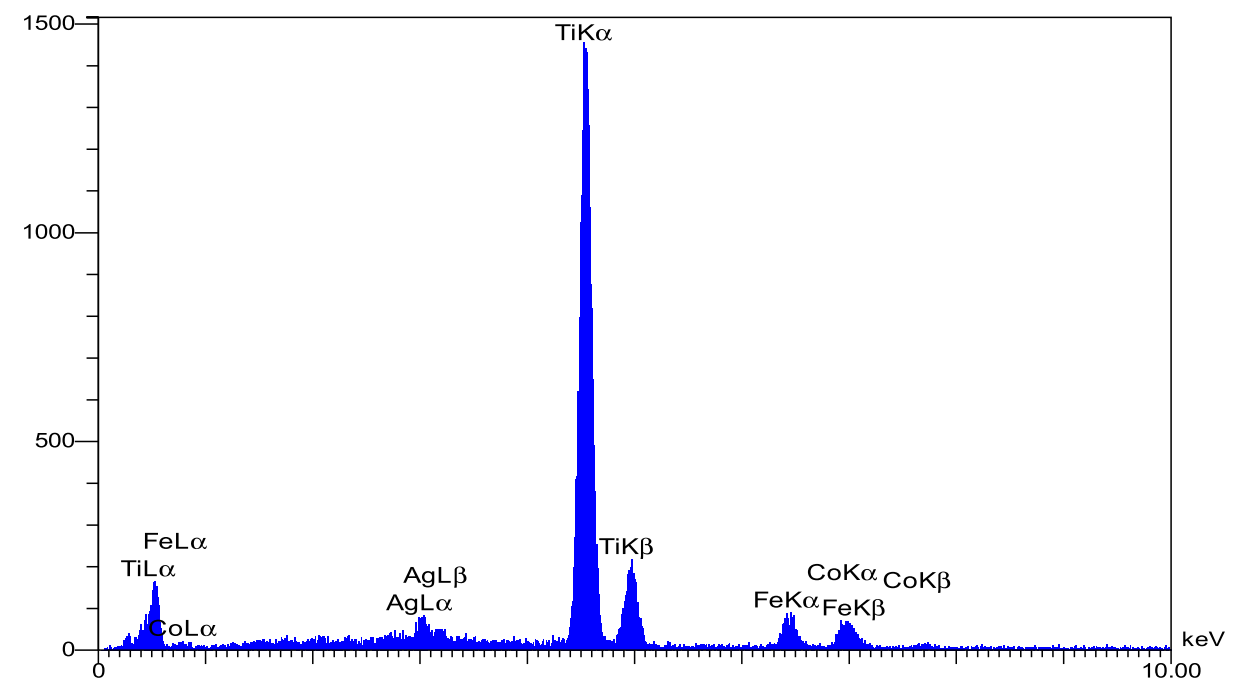

Fig. 7. EDX spectrum of TCA nanocomposite. 

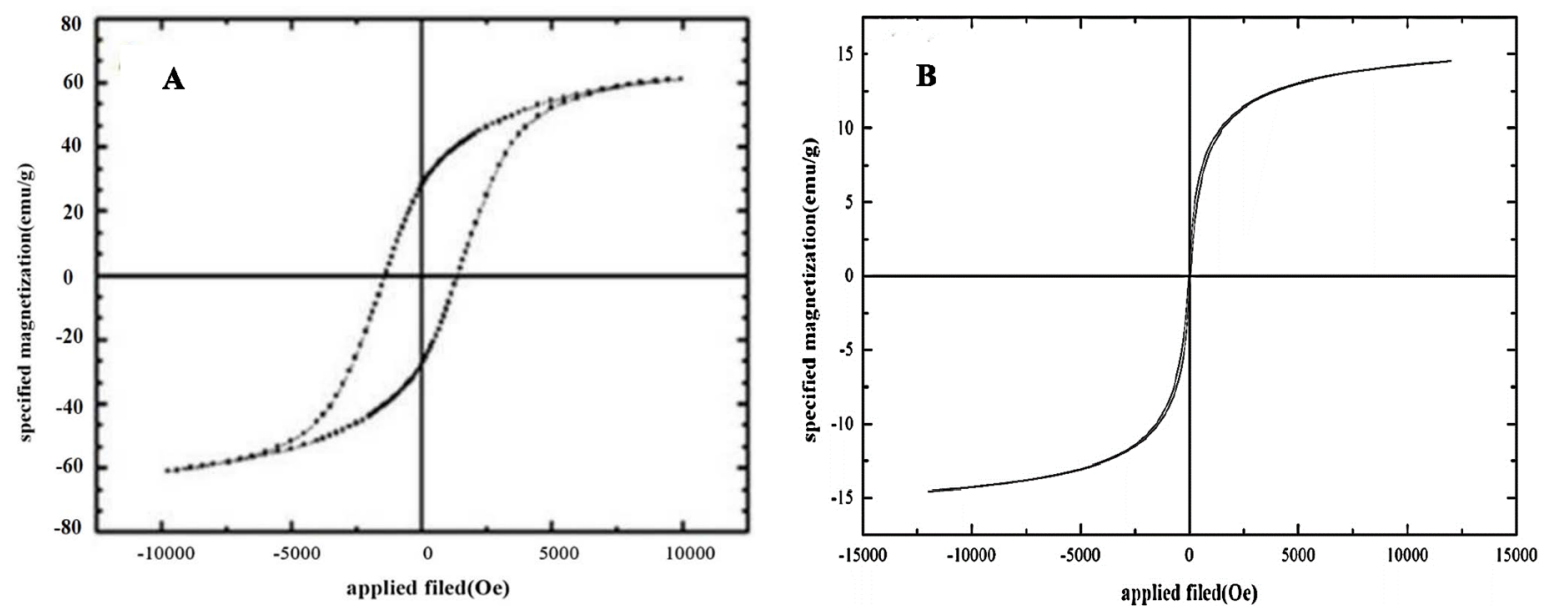

Fig. 8. Hysteresis loops for $\mathrm{CoFe}_{2} \mathrm{O}_{4}$ (A) and TCA (B).

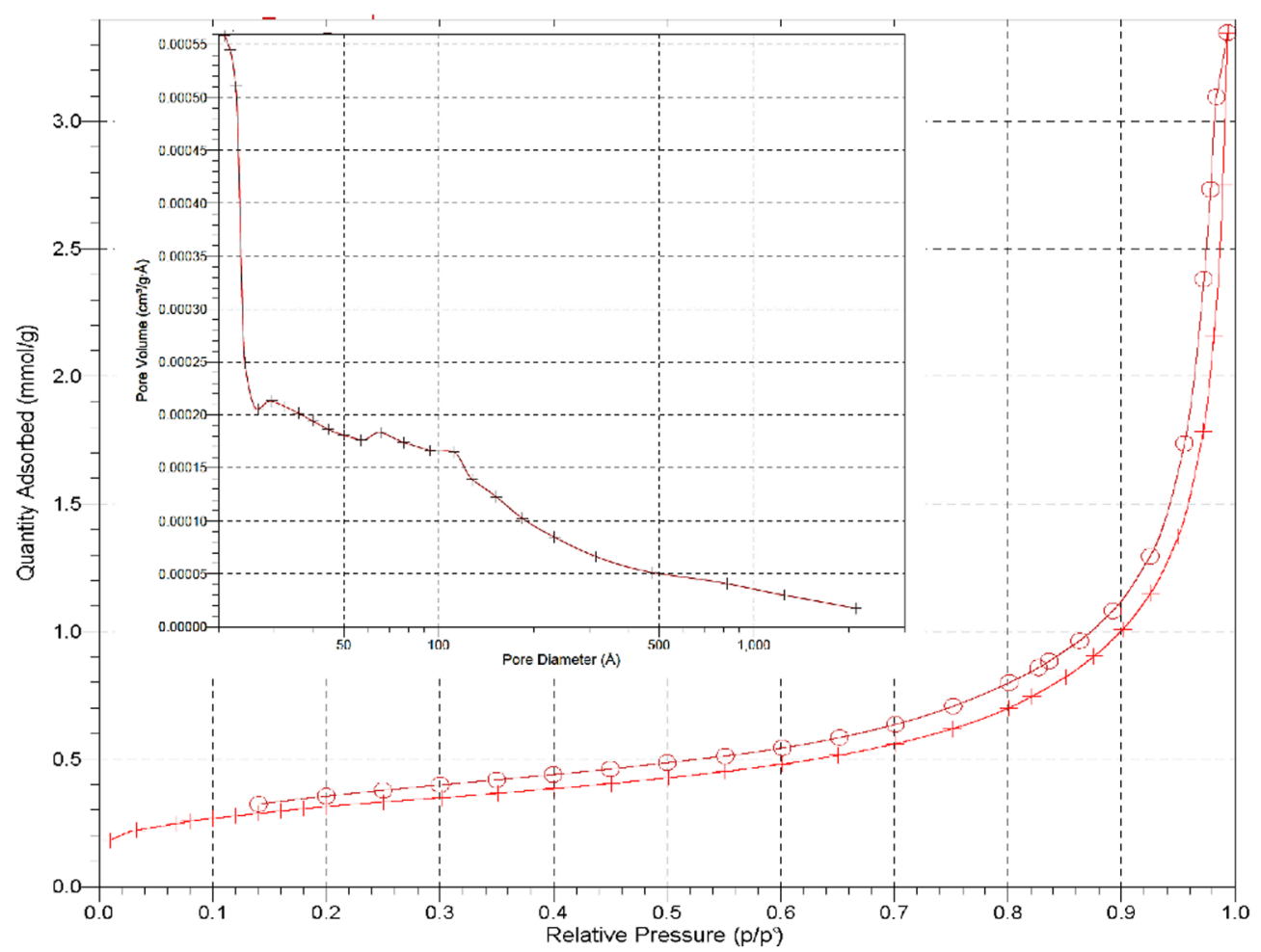

Fig. 9. Nitrogen sorption isotherm of TCA nanocomposite.

negative tubes was cultured on Mueller-Hinton Agar and incubated as previously described. Plus, minimum bactericidal concentration (MBC) was regarded as the least concentration that was able to prevent colony formation.

\subsection{Scanning probe microscopy (SPM) analysis}

SPM analysis was employed in order to research possible structural changes within the treated bacteria with TCA nanocomposite. The $100 \mu \mathrm{L}$ of $0.5 \mathrm{McF}$ arland suspension of every of $E$. coli and B. subtilis was smeared on a glass-slide and air dried, then analyzed by SPM. Simultaneously, the target bacteria separately treated with $2 \mathrm{mg} \cdot \mathrm{mL}^{-1}$ of the TCA nanocomposite and following overnight incubation at $37^{\circ} \mathrm{C}$, were analyzed as before described.

\section{Results and discussion}

\subsection{Microstructure observation and magnetic properties}

Among various magnetic materials, cobalt ferrite $\left(\mathrm{CoFe}_{2} \mathrm{O}_{4}\right)$ was applied on the surface of $\mathrm{TiO}_{2}$ to get TC composite. $\mathrm{CoFe}_{2} \mathrm{O}_{4}$ is a preferable choice rather than magnetite $\left(\mathrm{Fe}_{3} \mathrm{O}_{4}\right)$ because the latter is easily oxidized in air, or in alkaline solution whereas no precaution is required during the preparation and handling of the former [36]. Through two subsequent steps, the $\mathrm{TiO}_{2}$ core was first coated with $\mathrm{CoFe}_{2} \mathrm{O}_{4}$ and then with AgNPs to yield magnetic nanocomposite. The FT-IR spectrum of $\mathrm{TiO}_{2}$ (Fig. 1-A) shows a really broadband that emerges in a range of $800-450 \mathrm{~cm}^{-1}$, which is because of the vibration of Ti-O-Ti bonds in TiO lattice which shift to the lower wavenumbers after coating with $\mathrm{CoFe}_{2} \mathrm{O}_{4}$ (Fig. 1-D). The FT-IR spectrum of magnetic nanocomposite 


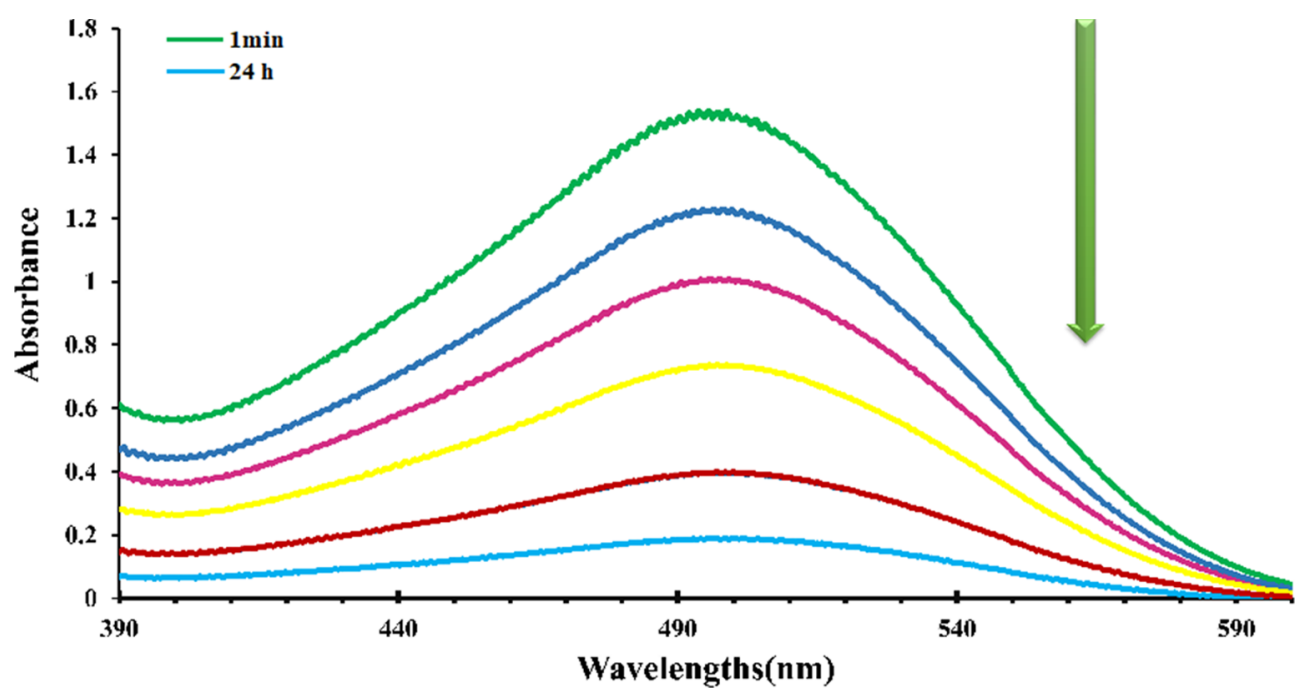

Fig. 10. The adsorption capability of TCA nanocomposite toward CR dye.

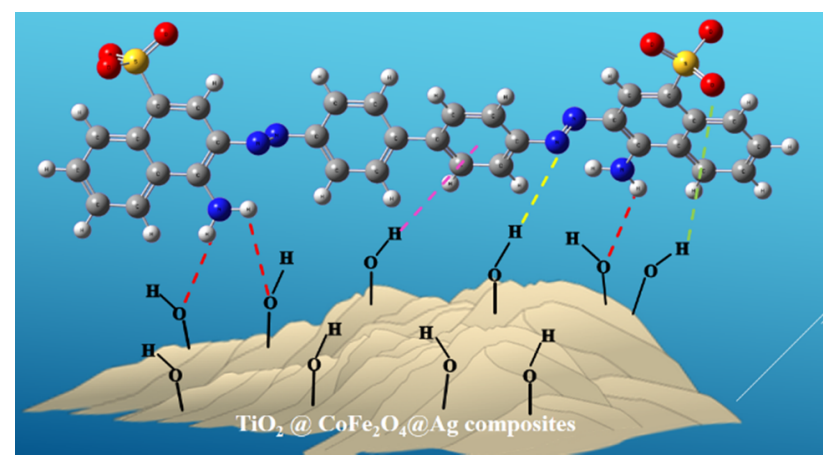

Scheme 1. Adsorption mechanism of Congo red (CR) dye using TCA nanocomposite.

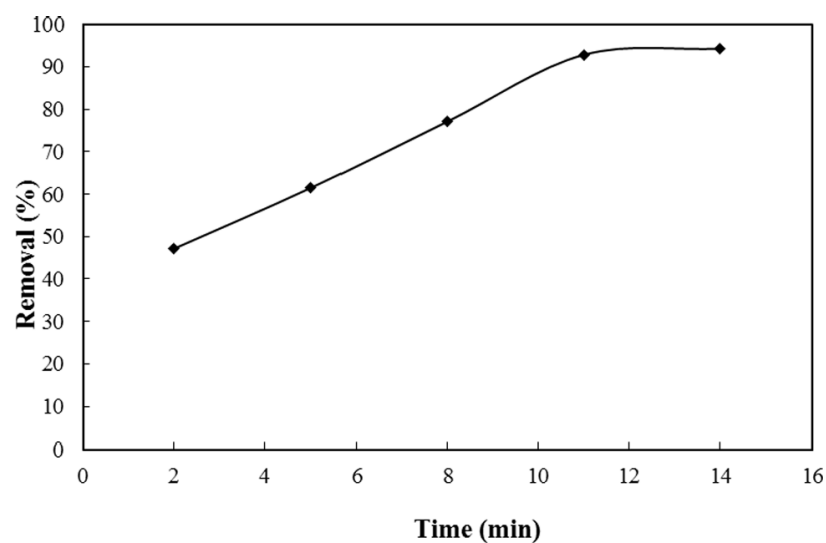

Fig. 11. Percentage removal of $\mathrm{CR}$ dye from aqueous solution onto magnetic nanocomposite at ambient temperature.

(Fig. 1-D) is more or less the identical as that of TCA (Fig. 1-C). The weak band centered at about $1600 \mathrm{~cm}^{-1}$ which observed in TCA and TC nanocomposites is attributed to the bending vibration mode of $\mathrm{H}_{2} \mathrm{O}$ remained within the samples. Figs. 2 and 3, show the XRD patterns of TCA nanocomposite and its components, respectively. The successful synthesis of TCA nanocomposite can be confirmed by the characteristic diffraction lines at $2 \theta=25.4^{\circ}\left(\mathrm{TiO}_{2}\right.$ anatase), $35^{\circ}$ (magnetite), and $38^{\circ}$ (silver).
For SEM and AFM photomicrographs of as-synthesized $\mathrm{CoFe}_{2} \mathrm{O}_{4}$, TC and TCA nanoparticles are illustrated in Figs. 4 and 5, respectively. The nanocomposite particles indicate relatively narrow particle size distribution with almost spherical morphology, and most of particles are smaller than $200 \mathrm{~nm}$. The AgNPs should be precipitated on the surface of $\mathrm{CoFe}_{2} \mathrm{O}_{4}$ coated $\mathrm{TiO}_{2}$, which cannot be clearly observed in the SEM image of TCA nanocomposite. Hence, for the aim of further explore the morphological and microstructural features of the TCA nanocomposite, TEM imaging technique was exploited (Fig. 6). As can be seen from the image, the surface of each TC sphere is inlaid with AgNPs. The AgNPs in the TEM micrograph appeared as clusters of well-crystallized near-circular shape nanocrystals with different thicknesses. To recognize the elemental composition of the as-prepared TCA nanocomposite particles, energy dispersive X-ray (EDX) analysis was performed on the SEM microstructure. The EDX spectrum, which is shown in Fig. 7, clearly reveals the presence of all main elements $(\mathrm{O}, \mathrm{Ti}, \mathrm{Fe}$, $\mathrm{Co}$ and $\mathrm{Ag}$ ) comprising this three-component composite. This finding, in combination with XRD, FT-IR and TEM results indicates the presence of $\mathrm{TiO}_{2}$ particles coated with the inner $\mathrm{CoFe}_{2} \mathrm{O}_{4}$ shell and outer AgNPs layer.

The magnetic properties of the TCA nanocomposite and $\mathrm{CoFe}_{2} \mathrm{O}_{4}$ were investigated by the VSM test at ambient temperature, in which the hysteresis loops are shown in Fig. 8. Pristine $\mathrm{CoFe}_{2} \mathrm{O}_{4}$ nanoparticles and TCA nanocomposite, respectively, have saturation magnetization $\left(\mathrm{M}_{\mathrm{s}}\right)$ values of 59.49, 20 and 15 emu.g ${ }^{-1}$. For the fact of the presence of nonmagnetic $\mathrm{TiO}_{2}$ core, the $\mathrm{M}_{\mathrm{s}}$ of TCA nanocomposite is lower than that of the naked $\mathrm{CoFe}_{2} \mathrm{O}_{4}$. Further decrease in $\mathrm{M}_{\mathrm{s}}$ value is observed for TCA nanocomposite which is attributed to the slight increase in the mass and size caused by the depositing of AgNPs on the surfaces of TC microspheres. It should be highlighted that although the $\mathrm{M}_{\mathrm{s}}$ value of $\mathrm{CoFe}_{2} \mathrm{O}_{4}$ drops remarkably on coating with AgNPs, the TCA nanocomposite still shows acceptable magnetization suggesting its suitability for magnetic separation and recovery.

The BET measurement for magnetic TCA nanocomposite is shown in Fig. 9, which the curve belonged to the IV Nitrogen adsorption isotherm whose adsorption curve is not coincident with desorption curve, and consequently, forming a hysteresis loop. This nitrogen changing isotherm exhibited the adsorption and desorption behavior of porous materials. Plus, the calculated specific surface area is $25.3819 \mathrm{~m}^{2} \cdot \mathrm{g}^{-1}$. The estimated pore size distribution is shown in the inset of Fig. 9, which observed that the pore size is concentrated at $97.4643 \AA$, and this result is attributed to a specific surface area. To sum up, the results suggest that the magnetic TCA nanocomposite has an excellent adsorption capability. 

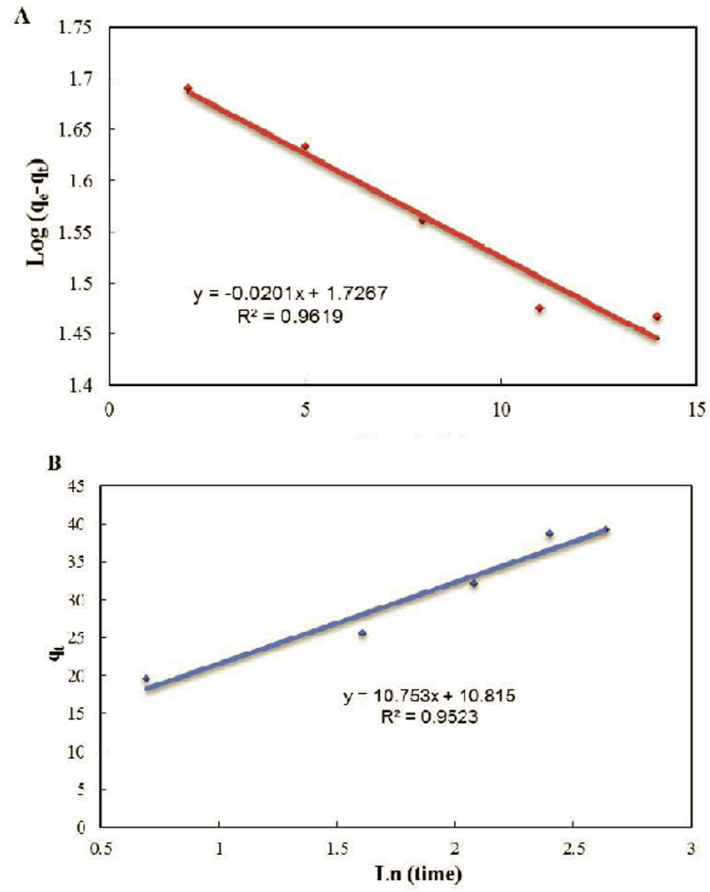
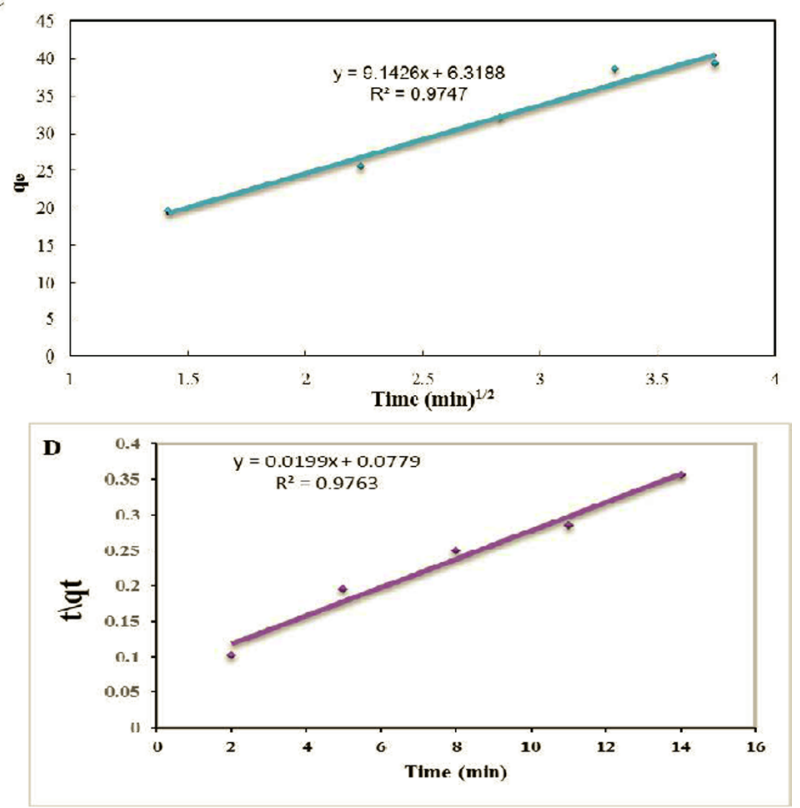

Fig. 12. Fits of the pseudo-first-order kinetics model (A), Elovich kinetics model (B), pseudo-second-order model (C) and intraparticle diffusion model (D) at initial CR dye concentration of $60 \mathrm{mg} \cdot \mathrm{L}^{-1}$

Table 1

Fitted kinetics parameters for adsorption of CR dye from aqueous solutions onto magnetic nanocomposite at ambient temperature.

\begin{tabular}{lll}
\hline Kinetic models & Equations & Adj. R-square \\
\hline Pseudo-first-order model & $q_{t}=q_{e}\left(1-e^{-k_{1} t}\right)$ & 0.96 \\
Pseudo-second-order model & $q_{t}=\frac{q_{e}^{2} k_{2} t}{\left(1=q_{e} k_{2} t\right)}$ & 0.97 \\
Intraparticle diffusion model & $q_{t}=x_{i}+k_{i} t^{1 / 2}$ & 0.96 \\
Elovich & $q_{t}=\frac{\ln \left(a_{e} b_{e}\right)}{b_{e}}+\frac{1}{b_{e}} \ln (t)$ & 0.95 \\
\hline
\end{tabular}

\subsection{Adsorption measurement of TCA nanocomposite}

A significant portion of commonly used dye are toxic and even carcinogenic. Several approaches have been adopted in the treatment of dyed-wastewater to decline the impacts on the environment, in which budget-saving, green adsorption-desorption technology is considered to be more competitive than the others. We chose different dye molecules to evaluate the absorption ability of TCA nanocomposite. The freshly synthesized $0.03 \mathrm{~g}$ of TCA nanocomposite was mixed into the $25 \mathrm{~mL}$ aqueous solution containing $50 \mathrm{mg} \cdot \mathrm{mL}^{-1}$ Congo red (CR) dye, which adsorption capabilities of TCA nanocomposite toward this dye was tested by UV-visible spectroscopy (Fig. 10). It is reported that the CR dye could be powerfully absorbed. For the absorption of CR, the color of the composites changed from brown to dark, red-brown, implying the existence of corresponding CR dye in the solid. About the adsorption mechanism between CR and TCA nanocomposite, it could be explained by means of the structures of anion dye and nanocomposites. As know, the amide groups are both hydrogen-bonding donors and acceptors that can facilitate interactions with the specific dyes. To further determine the adsorption mechanism, FT-IR spectrum of TCA nanocomposite was given in Fig. 1. The FT-IR spectrum displayed some of $\mathrm{OH}^{-}$groups on the surface of TCA nanocomposite. It is presumed that due to the formation of hydrogen-bonding between the dyes and TCA nanocomposite, $\mathrm{CR}$ shares $-\mathrm{NH}_{2}$ and $\mathrm{SO}_{3}{ }^{2-}$ groups. In this place, $\mathrm{CR}$ is likely to be attracted to the surface of TCA nanocomposite owing to dipole-dipole interactions between the hydrogen on the adsorbent surface and the electropositive groups on the dye structure, hydrogen bonding between the hydroxyl groups and aromatic rings, the nitrogen and oxygen atoms (Scheme 1). These absorption dye molecules could be released by ethanol solution after stirring the mixture for $1 \mathrm{~h}$.

\subsubsection{Adsorption kinetics}

To explicate the adsorption mechanism for CR dye from aqueous solution into the TCA nanocomposite, the pseudo-first-order, secondorder, Elovich and intraparticle diffusion models were exploited to estimate the results found from $\mathrm{CR}$ adsorption. In the following, the pseudo-first-order, pseudo-second-order, intraparticle diffusion and Elovich models are given as Eqs. (2), (3), (4) and (5), respectively [37-40].

$q_{t}=q_{e}\left(1-e^{-k_{1} t}\right)$

$q_{t}=\frac{q_{e}{ }^{2} k_{2} \mathrm{t}}{\left(1+q_{e} k_{2} \mathrm{t}\right)}$

$q_{t}=x_{i}+k_{i} t^{1 / 2}$

$q_{t}=\frac{\ln \left(a_{e} b_{e}\right)}{b_{e}}+\frac{1}{b_{e}} \ln (t)$

The experimental plot of adsorption $q_{t}$ over time $t$ with $60 \mathrm{mg} \cdot \mathrm{L}^{-1}$ initial concentrations of CR are shown in Fig. 11, which displays a good potential application of TCA nanocomposite for the adsorption of CR. Fig. 12(A-D) shows the fitted curve of adsorption kinetics models for CR into the mentioned magnetic nanocomposites with initial concentration of $60 \mathrm{mg} . \mathrm{L}^{-1}$ at ambient condition, $R^{2}$ kinetic parameter was calculated from the fits of the four kinetic models that listed in Table 1 . The produced results demonstrated that the pseudo-second-order model is consistent with the experimental result quite well, and its correlation coefficient $\left(R^{2}\right)$ value is recorded the maximum amount. Compared with the pseudo-second-order model, lower $R^{2}$ values for the pseudofirst-order and intraparticle diffusion kinetic models reveal the good fittings. So, the pseudo-second-order model could explain well the adsorption process of CR onto the TCA nanocomposite. 

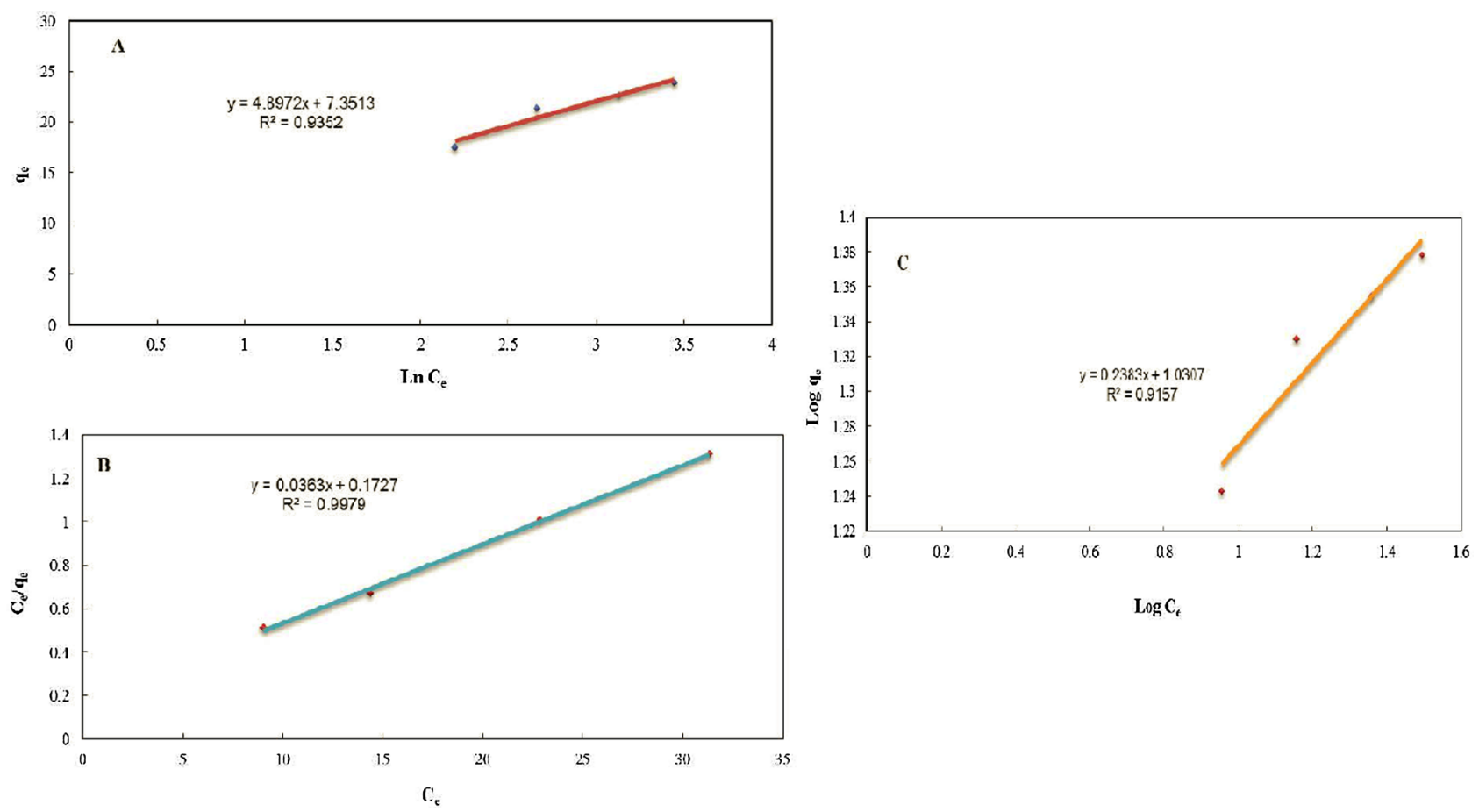

Fig. 13. The Temkin (A), Langmuir (B) and Freundlich (C) adsorption isotherms of CR dye from aqueous solution onto magnetic nanocomposite at ambient temperature.

Table 2

Evaluated model parameters of adsorption isotherms for CR dye onto magnetic nanocomposite at ambient temperature.

\begin{tabular}{lll}
\hline Models & Equations & Adj. R-square \\
\hline Langmuir & $q_{e}=\frac{q_{\max } C_{e} k_{L}}{\left(1+C_{e} k_{L}\right)}$ & 0.99 \\
Freundlich & $q_{e}=k_{F} C_{e}^{1 / n}$ & 0.91 \\
Temkin & $q_{e}=B \ln \left(A_{t} C_{e}\right)$ & 0.93 \\
D-R & $\mathrm{q}_{\mathrm{e}}=\mathrm{qexp}\left(-B S^{2}\right)$ & 0.841 \\
H-J & $\frac{1}{\mathrm{q}_{\mathrm{e}}^{2}}=\left[\frac{\mathrm{B}}{\mathrm{A}}\right]-\left[\frac{1}{\mathrm{~A}}\right] \log \mathrm{C}_{\mathrm{e}}$ & 0.731 \\
& & \\
\hline
\end{tabular}

\subsubsection{Adsorption isotherms}

The adsorption isotherm is important for understanding how molecules of adsorbent interact with the adsorbent surfaces. Hence, three adsorption isotherms were selected to fit the equilibrium data of $\mathrm{CR}$ adsorption onto the mentioned magnetic composite, which are namely Freundlich, Temkin, Dubinin-Radushkevitch (D-R), Harkins-Jura (H-J) and Langmuir express by Eqs. [37-40]:

$q_{e}=\frac{q_{\max } C_{e} k_{L}}{\left(1+C_{e} k_{L}\right)}$

$q_{e}=k_{F} C_{e}^{1 / n}$

$q_{e}=\operatorname{Bln}\left(A_{t} C_{e}\right)$

$\mathrm{q}_{\mathrm{e}}=\mathrm{qexp}\left(-B S^{2}\right)$

$\frac{1}{\mathrm{q}_{\mathrm{e}}^{2}}=\left[\frac{\mathrm{B}}{\mathrm{A}}\right]-\left[\frac{1}{\mathrm{~A}}\right] \log \mathrm{C}_{\mathrm{e}}$

The Langmuir, Freundlich and Temkin adsorption isotherms of CR of the magnetic TCA nanocomposite at ambient temperature are depicted in Fig. 13. The calculated parameter $\left(R^{2}\right)$ of Freundlich, Temkin, $\mathrm{D}-\mathrm{R}, \mathrm{H}-\mathrm{J}$ and Langmuir for the adsorption isotherms are listed in Table 2. By comparing the $R^{2}$ for five models, the Langmuir model is proved to be the best fit. By the way, the correlation coefficients of D-R,
$\mathrm{H}-\mathrm{j}$, Temkin and Freundlich isotherm equations are relatively lower, which as a consequence, these isotherm models are not appropriate to describe the adsorption equilibrium processes and mechanisms. In other words, the Langmuir isotherm is well-suited to model for giving information about the adsorption equilibrium of CR from aqueous solution onto the magnetic TCA nanocomposite. In the theoretical side, with regards to the Langmuir model, the adsorbent of the magnetic composites interacts with adsorbate of $\mathrm{CR}$ and adsorption which might be a monolayer absorbing mechanism.

\subsection{Photocatalytic activity testing of TCA nanocomposite}

The MB and RB dye were selected in order to evaluate the photocatalytic potential of the TCA nanocomposite and the influence of molecule type to be degraded by relation to the characteristics of the synthesized photocatalyst. In Fig. 14 (A and B), it displays a decrease in the adsorbent of the $\mathrm{MB}$ and $\mathrm{RB}$ dye versus time in the presence of sintered TCA nanocomposite under UV illumination. According to these results, $\mathrm{RB}$ and $\mathrm{MB}$ dye are degraded with TCA nanocomposite. As depicted, MB dye photodegradation is faster than RB dye photodegradation due to the fact that $\mathrm{RB}$ dye molecules are stable in relation to MB dye, for their differences in structures, as seen in Fig. 15 (A and B). The investigation from the accessible literature on photodegradation, the following relationship between the structure and decomposition can be found. The detected order was xanthene (RB) < Heteropolyaromatic (MB). This result is critical because it was demonstrated that the synthesized nanocomposite exhibits selectivity (i.e. photocatalytic efficiency depends on the compound to be degraded, whereas $\mathrm{MB}$ and $\mathrm{RB}$ dye photodegradation profiles are different from those synthesized materials). The mechanism of cationic dye decoloration via TCA nanocomposite is depicted in scheme 2.

\subsection{Antibacterial measurement}

The MIC and MBC indices of the TCA nanocomposite are showed in Fig. 16. These results proved that TCA nanocomposite displays a good antimicrobial activity against all the faced gram-positive and gram- 
A

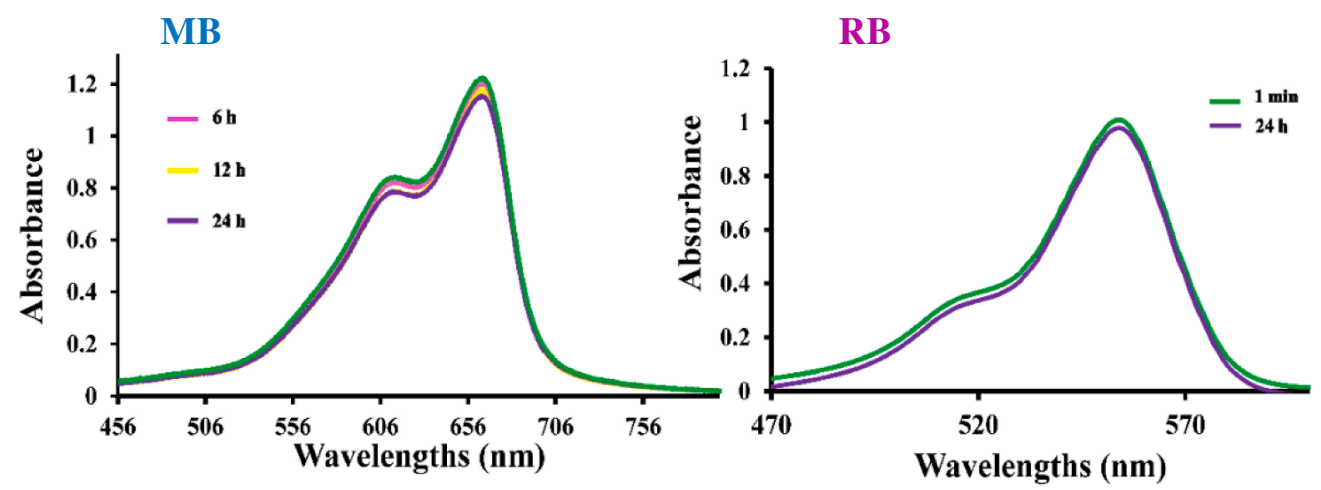

B
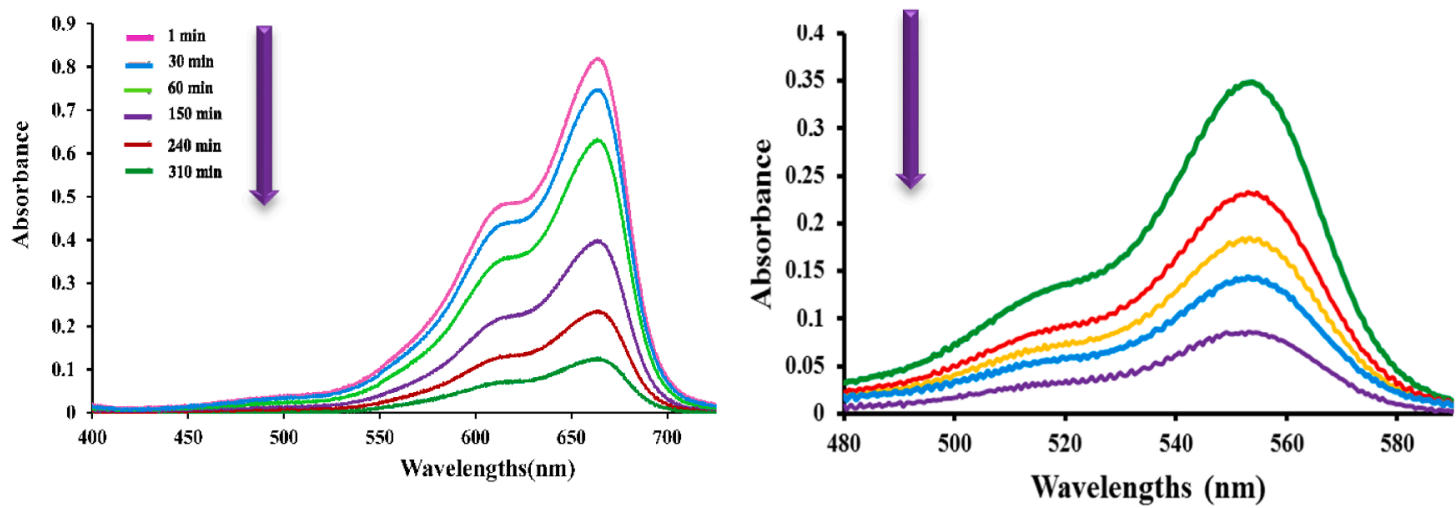

Fig. 14. The adsorption (A) and photodegradation (B) capabilities of TCA nanocomposite of MB and RB dye.

A

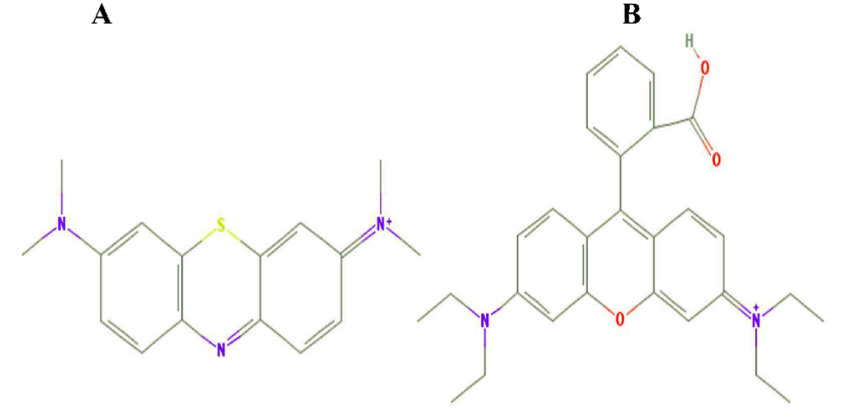

Fig. 15. The structures of $M B$ and $R B$ dye were illustrated in $A$ and $B$, respectively.

negative bacterial species. Additionally, the indices of TCA nanocomposite demonstrated for all examined bacteria are identical and equal to $1.0 \mathrm{mg} \cdot \mathrm{mL}^{-1}$. Thus, the TCA nanocomposite can be considered as an excellent antibacterial agent with broad spectrum of bacteriostatic ability for both gram-positive and gram-negative bacteria. Surprisingly, the MBC index of this nanocomposite is equal to MIC index in E. coli, P.aeruginosa and B.subtilis which means this agent is a potent bactericidal agent that can eliminate treated bacteria. In case of S.aureus, the MBC index is found to be as much as $4 \mathrm{mg} \cdot \mathrm{mL}^{-1}$. This is due the fact that more than $90 \%$ of tetrapeptide chains in this species are involved in cross linkage of peptidoglycan and hence improve bacterial resistance to antibacterial agents. So, in this case, the MBC is found approximately four times higher than MIC. In addition, TCA is a magnetic nanocomposite, which can be recovered from water solution via magnetic separator without any difficulties.

The isolated nanocomposite, through magnetic decantation, can be reused in a new disinfection procedure. Hence, because of the efficient isolation of these AgNPs-rich nanocomposite, the release of waste and probable contamination of disinfectant to the environment are avoided. The main reason of antimicrobial activity enhancement of AgNPs has not been disclosed yet, besides of several mechanisms have been proposed recently [41-43].

With regards to the proposed mechanism, the antibiotics and/or nanocomposite act on the cell wall, through its verity functional groups. This will be caused to cell wall lysis and, consequently, raise the penetration of AgNPs carrier composite into the bacterium. The TCA can then react with DNA and prevents its unwinding, which results in more serious damage to bacterial cells. The suggested mechanism for explaining the synergistic impact is solely a tentative one and more experimental and/or computational studies are required to explain the mechanism of this interesting effect in more detail.

The outcomes of SPM analysis of untreated and treated bacterial cells with TCA have been presented in Fig. 17. The lock-in-amplitude image is proved moderately structured membrane surface of the untreated bacterium. Untreated bacterial cells have typical rod shapes, while in the treated ones; rod to cocci cell deformity has been happened. In addition to that, cell lysis and bacterial death are found due to the obtained results. These observations confirm that this composite can affect SEDS proteins (i.e., those proteins that are responsible for shape, elongation, division and sporulation). These proteins play an important role in bacterial cytoskeleton formation, cell wall growth, peptidoglycan polymerization, transpeptidation of tetrapeptide side chains and also septum formation. So, if they are affected by chemical and/or natural compounds, the shape and growth of the bacterial cell will be having changes. As a consequent, the structural altering and deformation will be the main outcome of bacterial exposure with such TCA nanocomposite.

The obtained results All catalysts were effective for the inactivation of four bacteria, which is considered as an opportunistic pathogen highly resistant in various water treatments. 

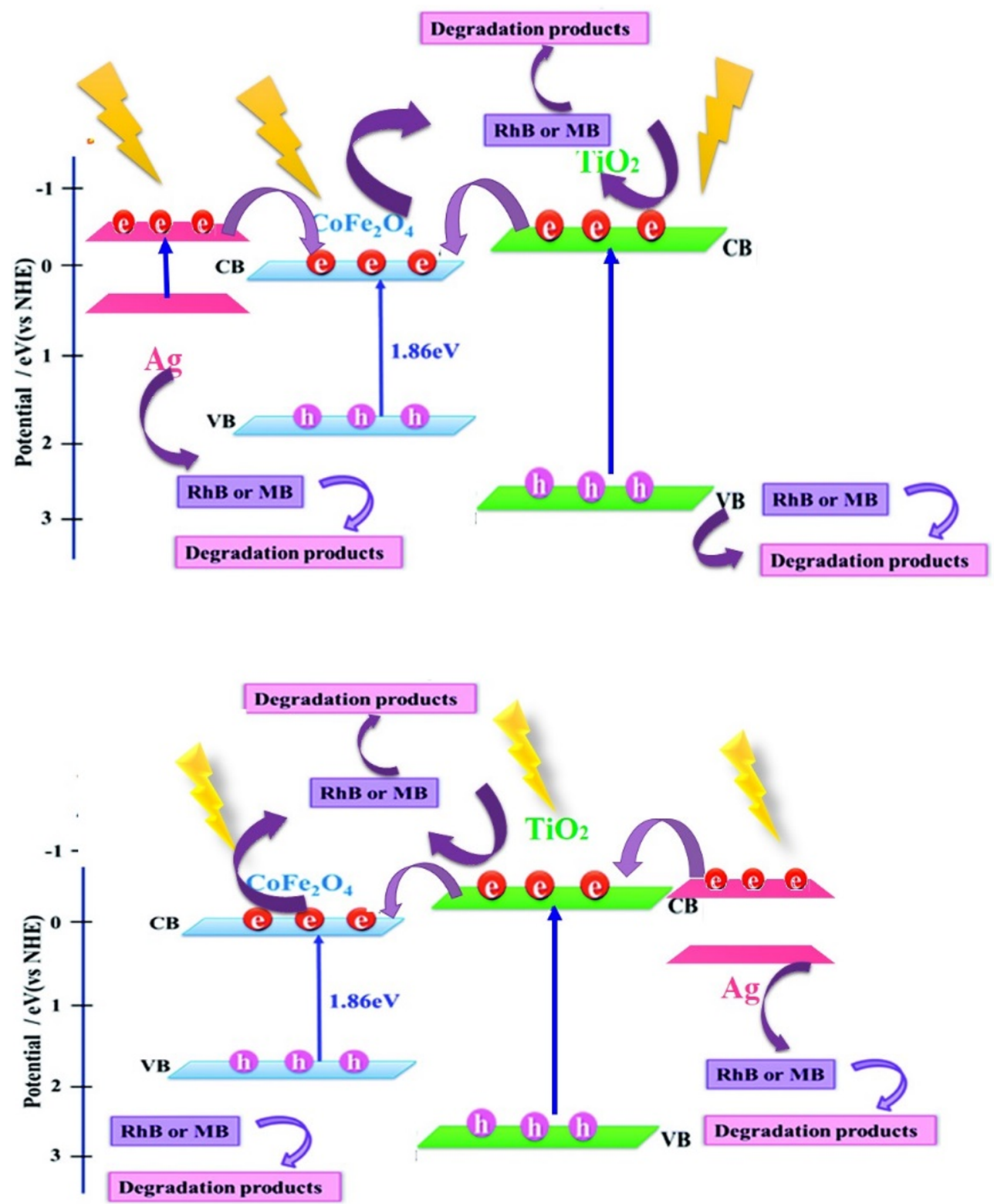

Scheme 2. Photodegradation mechanism of dye using TCA nanocomposite.

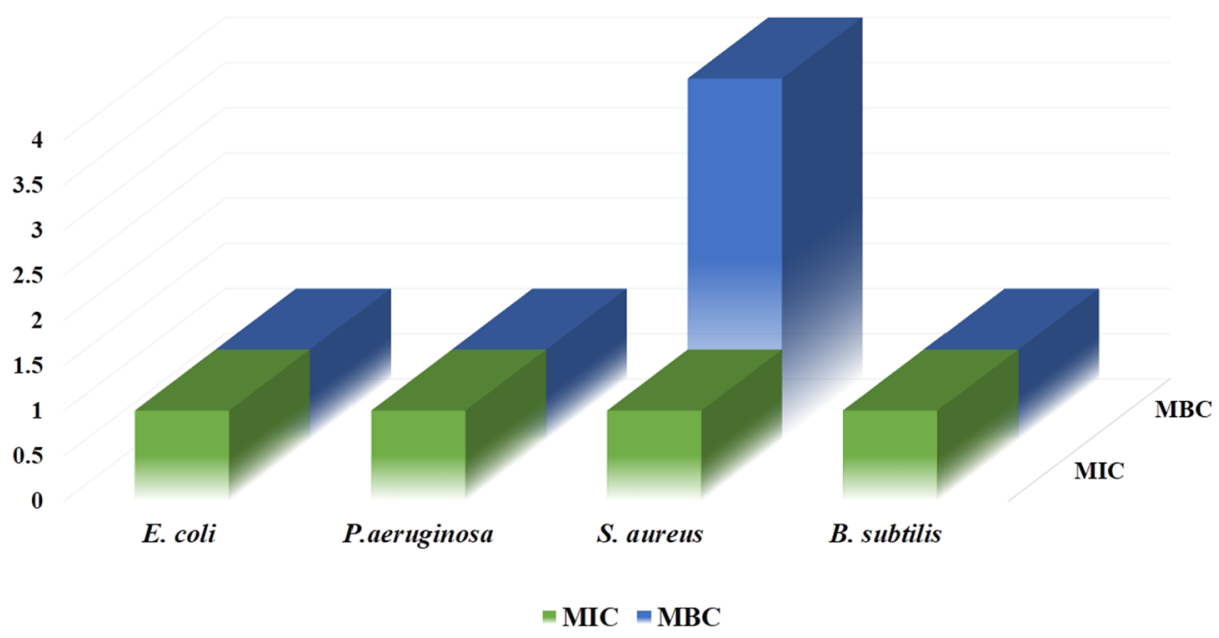

Fig. 16. Antibacterial activity of TCA nanocomposite. 


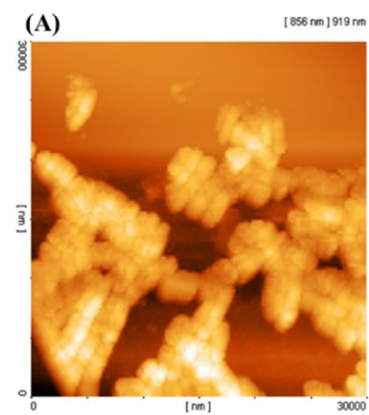

(B)
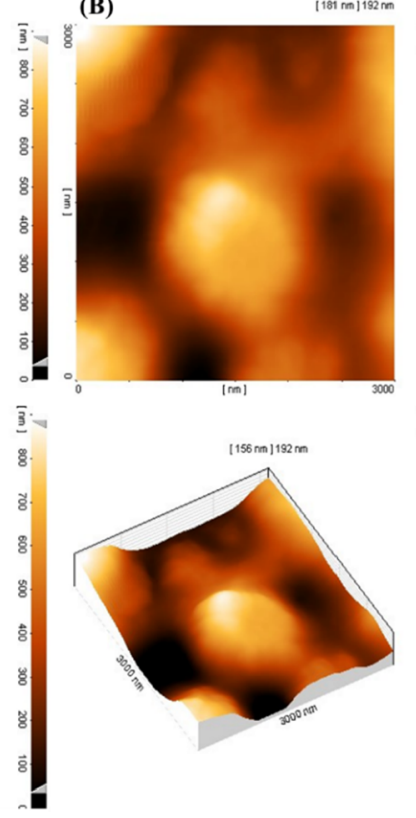

(C)
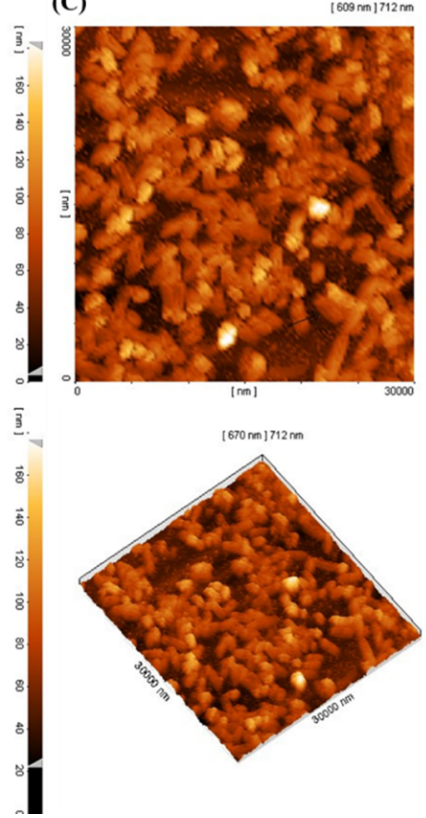

(D)

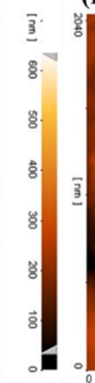

茎坾

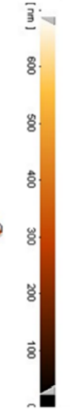

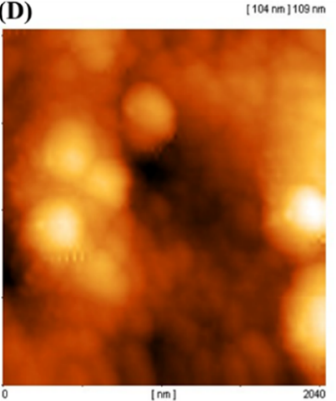
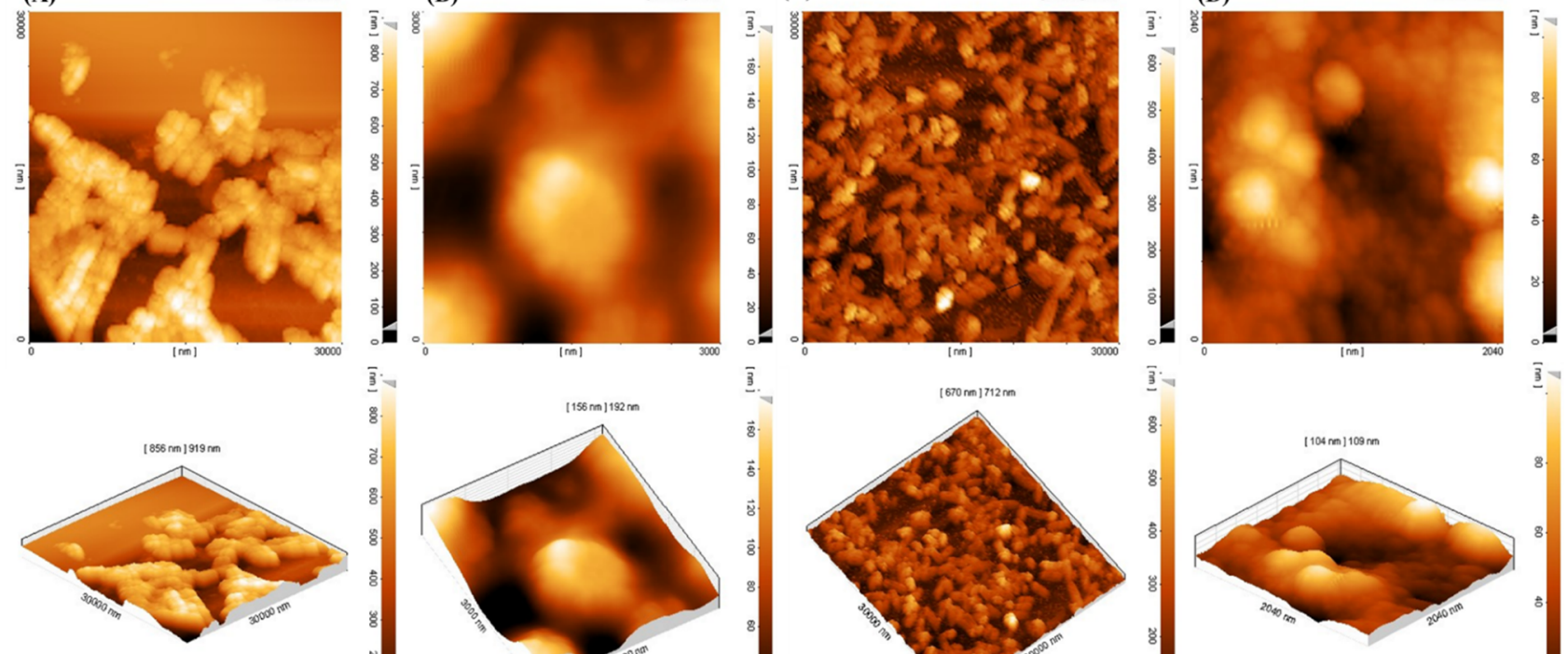

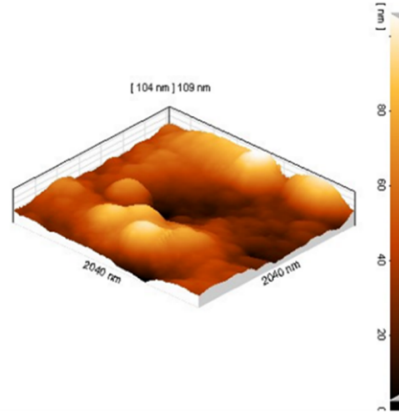

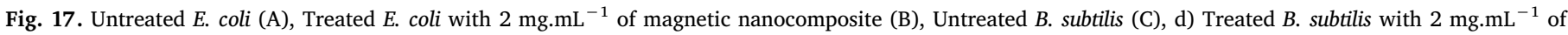
magnetic nanocomposite (D).

\section{Conclusion}

In this research, a fabric was designed possessing phototonic, biologic, magnetic and removal properties by in situ synthesis of magnetic nanocomposites. $\mathrm{TiO}_{2} @ \mathrm{CoFe}_{2} \mathrm{O}_{4} @ \mathrm{Ag}$ (TCA) nanocomposite showed photocatalytic activity for $\mathrm{MB}$ and $\mathrm{RB}$ photodecomposition under UV light irradiation. The pseudo-second-order kinetic model and Longmire isotherm were match with the adsorption process of CR from aqueous solvent onto the magnetic nanocomposites at ambient temperature. The main aim of the present work is to synthesize a new nanocomposite material and the study of its synergistic effect with dye and microbial pollutants. All in all, the obtained results revealed that these goals have been successfully pursued.

However, although photocatalysts are used for wastewater treatment, they can act as a pollutant in water if they will not be removed. TCA nanocomposite, also, predicted for collection from large scale operational environments in addition to laboratory scale treatment, which one of the best ways is magnetic removal. In future research, it is recommended that to establish an assessment based on the disadvantages and advantages of magnetic removal of TCA nanocomposite, and also draw a comparison between different removal methods in accordance with the efficiency, reusing capability, etc. Additionally, there is a gap to understand better the establishment concept of TCA nanocomposite (i.e. usage protocols) in wastewater treatment which needs more research and study.

\section{Declaration of Competing Interest}

The authors declared that there is no conflict of interest.

\section{References}

[1] Y.R. Yao, W.Z. Huang, H. Zhou, H.Y. Yin, Y.F. Zheng, X.C. Song, A novel $\mathrm{Fe}_{3} \mathrm{O}_{4} @$ $\mathrm{SiO}_{2} @ \mathrm{BiOBr}$ photocatalyst with highly active visible light photocatalytic properties, Mater. Chem. Phys. 148 (3) (2014) 896-902.

[2] J. Li, W. Ma, C. Chen, J. Zhao, H. Zhu, X. Gao, Photodegradation of dye pollutants on one-dimensional $\mathrm{TiO}_{2}$ nanoparticles under UV and visible irradiation, J. Mol. Catal. A: Chem. 261 (1) (2007) 131-138.

[3] C.J. Li, J.N. Wang, B. Wang, J.R. Gong, Z. Lin, Direct formation of reusable $\mathrm{TiO}_{2} /$ $\mathrm{CoFe}_{2} \mathrm{O}_{4}$ heterogeneous photocatalytic fibers via two-spinneret electrospinning, J. Nanosci. Nanotechnol. 12 (3) (2012) 2496-2502.
[4] X. Li, J. Yu, J. Low, Y. Fang, J. Xiao, X. Chen, Engineering heterogeneous semiconductors for solar water splitting, J. Mater. Chem. A 3 (6) (2015) 2485-2534.

[5] R. Liu, Y. Tian, J. Xu, H. Fu, Y. Li, Efficient removal of congo red by magnetic $\mathrm{CoFe}_{2} \mathrm{O}_{4}$ nanoparticles prepared via the rapid combustion process, J. Nanosci. Nanotechnol. 16 (9) (2016) 9535-9543.

[6] Hussain, Z., Ameer, A., A., Ahmed, A., Abdullah, M., B., \& Yousif, E. (2015). Nanotitanium dioxide as photocatalytic degradation of pollutants. J. Chem. Pharmaceut. Res., 7(8), 522-530.

[7] A. Ibhadon, P. Fitzpatrick, Heterogeneous photocatalysis: recent advances and applications, Catalysts 3 (1) (2013) 189-218.

[8] N.M. Nursam, X. Wang, R.A. Caruso, High-throughput synthesis and screening of titania-based photocatalysts, ACS Comb. Sci. 17 (10) (2015) 548-569.

[9] J. Wen, X. Li, W. Liu, Y. Fang, J. Xie, Y. Xu, Photocatalysis fundamentals and surface modification of $\mathrm{TiO}_{2}$ nanomaterials, Chin. J. Catal. 36 (12) (2015) 2049-2070.

[10] M. Pelaez, N.T. Nolan, S.C. Pillai, M.K. Seery, P. Falaras, A.G. Kontos, M.H. Entezari, A review on the visible light active titanium dioxide photocatalysts for environmental applications, Appl. Catal. B 125 (2012) 331-349.

[11] G. Yang, J.J. Zhu, K. Okitsu, Y. Mizukoshi, B.M. Teo, N. Enomoto, S.H. Sonawane, Handbook of ultrasonics and sonochemistry, Springer Singapore, 2016, p. 295)..

[12] Z.F. Yin, L. Wu, H.G. Yang, Y.H. Su, Recent progress in biomedical applications of titanium dioxide, PCCP 15 (14) (2013) 4844-4858.

[13] H. Park, Y. Park, W. Kim, W. Choi, Surface modification of $\mathrm{TiO}_{2}$ photocatalyst for environmental applications, J. Photochem. Photobiol., C 15 (2013) 1-20.

[14] Jodat, A., ALIZAD, N. M., \& Ghamkhari, M. (2014). Comparison of photocatalytic activities of two different dyes using Pt-modified TiO2 nanoparticles under visible light.

[15] A.M. Algubili, E.M. Alrobayi, A.F. Alkaim, Photocatalytic degradation of remazol brilliant blue dye by ZnO/UV process, Int. J. Chem. Sc. 13 (2) (2015) 911-921.

[16] A. Ajmal, I. Majeed, R.N. Malik, H. Idriss, M.A. Nadeem, Principles and mechanisms of photocatalytic dye degradation on $\mathrm{TiO}_{2}$ based photocatalysts: a comparative overview, RSC Adv. 4 (70) (2014) 37003-37026.

[17] X.Y. Li, J.N. Wang, L.L. Zhang, C.J. Li, Photocatalytic activity of magnetically separable La-doped $\mathrm{TiO}_{2} / \mathrm{CoFe}_{2} \mathrm{O}_{4}$ nanofibers prepared by two-spinneret electrospinning, J. Mater. Sci. 47 (1) (2012) 465-472.

[18] Nurhidayatullaili Muhd Julkapli, Samira Bagheri, Sharifah Bee Abd Hamid, Recent Advances in Heterogeneous Photocatalytic Decolorization of Synthetic Dyes, Sci. World J. 2014 (2014) 1-25, https://doi.org/10.1155/2014/692307.

[19] M.S. Secula, G.D. Suditu, I. Poulios, C. Cojocaru, I. Cretescu, Response surface optimization of the photocatalytic decolorization of a simulated dyestuff effluent, Chem. Eng. J. 141 (1-3) (2008) 18-26.

[20] W. Wang, Y. Liu, J. Qu, Y. Chen, M.O. Tadé, Z. Shao, Synthesis of Hierarchical $\mathrm{TiO}_{2}-\mathrm{C}_{3} \mathrm{~N}_{4}$ Hybrid Microspheres with Enhanced Photocatalytic and Photovoltaic Activities by Maximizing the Synergistic Effect, ChemPhotoChem 1 (1) (2017) 35-45.

[21] Y. Kim, H.M. Hwang, L. Wang, I. Kim, Y. Yoon, H. Lee, Solar-light photocatalytic disinfection using crystalline/amorphous low energy bandgap reduced $\mathrm{TiO}_{2}$, Sci. Rep. 6 (2016) 25212.

[22] T.H. Tan, J. Scott, Y.H. Ng, R.A. Taylor, K.F. Aguey-Zinsou, R. Amal, Understanding plasmon and band gap photoexcitation effects on the thermal-catalytic oxidation of ethanol by $\mathrm{TiO}_{2}$-supported gold, ACS Catal. 6 (3) (2016) 1870-1879.

[23] M. Sboui, S. Bouattour, M. Gruttadauria, L.F. Liotta, V. La Parola, S. Boufi, Hybrid 
paper- $\mathrm{TiO}_{2}$ coupled with a $\mathrm{Cu}_{2} \mathrm{O}$ heterojunction: an efficient photocatalyst under sun-light irradiation, RSC Adv. 6 (90) (2016) 86918-86929.

[24] E. Liu, L. Kang, Y. Yang, T. Sun, X. Hu, C. Zhu, J. Fan, Plasmonic Ag deposited $\mathrm{TiO}_{2}$ nano-sheet film for enhanced photocatalytic hydrogen production by water splitting, Nanotechnology 25 (16) (2014) 165401.

[25] H. Yan, X. Wang, M. Yao, X. Yao, Band structure design of semiconductors for enhanced photocatalytic activity: the case of $\mathrm{TiO}_{2}$, Progress Nat. Sci. Mater. Int. 23 (4) (2013) 402-407.

[26] W.F. Ma, Y. Zhang, L.L. Li, L.J. You, P. Zhang, Y.T. Zhang, C.C. Wang, Tailor-made magnetic $\mathrm{Fe}_{3} \mathrm{O}_{4} @ \mathrm{mTiO}_{2}$ microspheres with a tunable mesoporous anatase shell for highly selective and effective enrichment of phosphopeptides, ACS Nano 6 (4) (2012) 3179-3188.

[27] Y.T. Woo, D. Lai, J.L. McLain, M.K. Manibusan, V. Dellarco, Use of mechanismbased structure-activity relationships analysis in carcinogenic potential ranking for drinking water disinfection by-products, Environ. Health Perspect. 110 (suppl 1) (2002) 75-87.

[28] X. Liu, F. Wang, A. Niazov-Elkan, W. Guo, I. Willner, Probing biocatalytic transformations with luminescent DNA/silver nanoclusters, Nano Lett. 13 (1) (2012) 309-314.

[29] G. Ghodake, S.R. Lim, D.S. Lee, Casein hydrolytic peptides mediated green synthesis of antibacterial silver nanoparticles, Colloids Surf., B 108 (2013) 147-151.

[30] Nurit Beyth, Yael Houri-Haddad, Avi Domb, Wahid Khan, Ronen Hazan, Alternative Antimicrobial Approach: Nano-Antimicrobial Materials, Evidence-Based Complementary and Alternative Medicine 2015 (2015) 1-16, https://doi.org/10. $1155 / 2015 / 246012$.

[31] A.M. Holmes, J. Lim, H. Studier, M.S. Roberts, Varying the morphology of silver nanoparticles results in differential toxicity against micro-organisms, HaCaT keratinocytes and affects skin deposition, Nanotoxicology 10 (10) (2016) 1503-1514.

[32] J. Helmlinger, C. Sengstock, C. Groß-Heitfeld, C. Mayer, T.A. Schildhauer, M. Köller, M. Epple, Silver nanoparticles with different size and shape: equal cytotoxicity, but different antibacterial effects, RSC Adv. 6 (22) (2016) 18490-18501.

[33] K.S. Rajkumar, N. Kanipandian, R. Thirumurugan, Toxicity assessment on haemotology, biochemical and histopathological alterations of silver nanoparticles- exposed freshwater fish Labeo rohita, Appl. Nanosci. 6 (1) (2016) 19-29.

[34] M. Malekshahi Byranvand, A. Nemati Kharat, L. Fatholahi, Z. Malekshahi Beiranvand, A review on synthesis of nano- $\mathrm{TiO}_{2}$ via different methods, $\mathrm{J}$. Nanostruct. 3 (1) (2013) 1-9.

[35] X. Cao, L. Gu, X. Lan, C. Zhao, D. Yao, W. Sheng, Spinel $\mathrm{ZnFe}_{2} \mathrm{O}_{4}$ nanoplates embedded with Ag clusters: preparation, characterization, and photocatalytic application, Mater. Chem. Phys. 106 (2-3) (2007) 175-180.

[36] Y.H. Deng, C.C. Wang, J.H. Hu, W.L. Yang, S.K. Fu, Investigation of formation of silica-coated magnetite nanoparticles via sol-gel approach, Colloids Surf., A 262 (1-3) (2005) 87-93.

[37] S.E. Moradi, S. Dadfarnia, A.M. Haji Shabani, S. Emami, Removal of congo red from aqueous solution by its sorption onto the metal organic framework MIL-100 (Fe): equilibrium, kinetic and thermodynamic studies, Desalin. Water Treat. 56 (3) (2015) 709-721.

[38] Y.S. Ho, G. McKay, Pseudo-second order model for sorption processes, Process Biochem. 34 (5) (1999) 451-465.

[39] M. Özacar, İ.A. Sengil, A kinetic study of metal complex dye sorption onto pine sawdust, Process Biochem. 40 (2) (2005) 565-572.

[40] J. Sharifi-Rad, S.M. Hoseini-Alfatemi, M. Sharifi-Rad, M. Iriti, Antimicrobial synergic effect of Allicin and silver nanoparticles on skin infection caused by methicillin resistant Staphylococcus aureus spp, Annals Med. Health Sci. Res. 4 (6) (2014) 863-868.

[41] M.K. Rai, S.D. Deshmukh, A.P. Ingle, A.K. Gade, Silver nanoparticles: the powerful nanoweapon against multidrug-resistant bacteria, J. Appl. Microbiol. 112 (5) (2012) 841-852.

[42] G.A. Martinez-Castanon, N. Nino-Martinez, F. Martinez-Gutierrez, J.R. MartinezMendoza, F. Ruiz, Synthesis and antibacterial activity of silver nanoparticles with different sizes, J. Nanopart. Res. 10 (8) (2008) 1343-1348.

[43] A.M. Fayaz, K. Balaji, M. Girilal, R. Yadav, P.T. Kalaichelvan, R. Venketesan, Biogenic synthesis of silver nanoparticles and their synergistic effect with antibiotics: a study against gram-positive and gram-negative bacteria, Nanomed. Nanotechnol. Biol. Med. 6 (1) (2010) 103-109. 